Acta Crystallographica Section F

Structural Biology

and Crystallization

Communications

ISSN 1744-3091

\section{Purification, crystallization and preliminary X-ray study of the fungal laccase from Cerrena maxima}

Andrey V. Lyashenko, ${ }^{\mathrm{a}}$ Nadegda E. Zhukhlistova, ${ }^{a}$

Azat G. Gabdoulkhakov, ${ }^{a}$ Yuliya N. Zhukova, ${ }^{a}$ Wolfang Voelter, ${ }^{b}$ Viatcheslav N. Zaitsev, ${ }^{c}$ Isabel Bento, ${ }^{d}$ Elena V. Stepanova, ${ }^{\text {e }}$ Galina S. Kachalova, ${ }^{\text {f }}$ Ol'ga V.

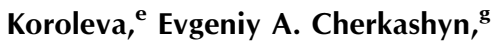
Vladimir I. Tishkov, ${ }^{\mathrm{g}}$ Victor S. Lamzin, ${ }^{\text {h }}$ Katja Schirwitz, ${ }^{\text {h }}$ Ekaterina Yu. Morgunova, ${ }^{a}$ Christian Betzel, ${ }^{i}$ Peter F. Lindley ${ }^{d}$ and Al'bert M. Mikhailov ${ }^{\text {** }}$

aA. V. Shubnikov Institute of Crystallography, RAS, Leninskiy Prospect 59, 119333 Moscow, Russia b Institute of Biochemistry, University of Tuebingen, Physiologisch-Chemisches Institut, Hoppe-SeylerStrasse 4, 72076 Tuebingen, Germany, 'University of St Andrews, Centre for Biomolecular Sciences, North Haugh, St Andrews, KY16 9ST, Scotland, Instituto de Tecnologia Química e Biológica (ITQB), Universidade Nova de Lisboa, Apartado 127, Av. Republica, 2781-901 Oeiras, Portugal, ${ }^{\mathbf{e}}$ A. N. Bakh Institute of Biochemistry, RAS, Leninskiy Prospect 33, 119071 Moscow, Russia, 'Institute of Theoretical and Experimental Biophysics of RAS, Institutskaya Street 3, 142290 Puschino, Moscow Region, Russia, ' ${ }^{\mathrm{D}}$ Departmen of Chemical Enzymology, M. V. Lomonosov Moscow State University, 119992 Moscow, Russia, hEuropean Molecular Biology Laboratory, c/o DESY, Notkestrasse 85, 22603 Hamburg, Germany, and 'University of Hamburg, Institute fur Biochemie und Lebensmittelchemie, Department of Biochemistry and Molecular Biology, c/o DESY, Building 22a, Notkestrasse 85, 22603 Hamburg, Germany

Correspondence e-mail: amm@ns.crys.ras.ru

Received 25 May 2006

Accepted 8 September 2006

PDB Reference: laccase, 2h5u, r2h5usf.

(C) 2006 International Union of Crystallography All rights reserved
Laccases are members of the blue multi-copper oxidase family that oxidize substrate molecules by accepting electrons at a mononuclear copper centre and transferring them to a trinuclear centre. Dioxygen binds to the trinuclear centre and, following the transfer of four electrons, is reduced to two molecules of water. Crystals of the laccase from Cerrena maxima have been obtained and X-ray data were collected to $1.9 \AA$ resolution using synchrotron radiation. A preliminary analysis shows that the enzyme has the typical laccase structure and several carbohydrate sites have been identified. The carbohydrate chains appear to be involved in stabilization of the intermolecular contacts in the crystal structure, thus promoting the formation of well ordered crystals of the enzyme. Here, the results of an X-ray crystallographic study on the laccase from the fungus Cerrena maxima are reported. Crystals that diffract well to a resolution of at least $1.9 \AA$ ( $R$ factor $=18.953 \% ; R_{\text {free }}=23.835$; r.m.s.d. bond lengths, $0.06 \AA$; r.m.s.d. bond angles, $1.07^{\circ}$ ) have been obtained despite the presence of glycan moieties. The overall spatial organization of $C$. maxima laccase and the structure of its copper-containing active centre have been determined by the molecular-replacement method using the laccase from Trametes versicolor (Piontek et al., 2002) as a structural template. In addition, four glycan-binding sites were identified and the $1.9 \AA$ X-ray data were used to determine the previously unknown primary structure of this protein. The identity (calculated from sequence alignment) between the $C$. maxima laccase and the $T$. versicolor laccase is about $87 \%$. Tyr196 and Tyr372 show significant extra density at the ortho positions and this has been interpreted in terms of $\mathrm{NO}_{2}$ substituents.

\section{Introduction}

Laccases (benzenediol oxygen oxidoreductases; EC 1.19.3.2) are widely distributed in higher plants and fungi. They belong to the family of multi-copper oxidases, which also includes ascorbate oxidase and ceruloplasmin. Laccases catalyze the oxidation of a broad range of different substrates, such as phenols, methoxysubstituted phenols, diamines and some inorganic compounds (Adman, 1991; Reinhammar, 1984; Thurston, 1994; Xu et al., 1996; Sakurai, 1992). These enzymes contain as least one mononuclear 'blue' copper site (T1 centre) and a trinuclear site comprising one type 2 copper and two type 3 coppers (T2/T3 centre). The three different copper types have been classified according to their optical and EPR spectra (Malmstrom, 1982). The catalytic mechanism for multi-copper oxidases generally involves the transfer of four electrons from the substrates attached to the $\mathrm{T} 1$ copper centre to the oxygen molecule bound to the T2/T3 centre, thus reducing dioxygen to two water molecules (Messerschmidt et al., 1992; Lindley, 2001; Bento et al., 2005).

The molecular properties of laccase and the nature of its coppercontaining active sites have been studied extensively by biochemical and spectroscopic methods over the last $50 \mathrm{y}$ (see, for example, reviews by Reinhammar, 1997; Mayer \& Staples, 2002). In most cases laccases are monomeric glycoproteins of around 500 amino acids with molecular weights in the range $60-85 \mathrm{kDa}$, depending on the carbohydrate content. For a long time, attempts to crystallize laccase for 
X-ray analysis were unsuccessful despite considerable efforts in several laboratories. The major problem was attributed to the presence of carbohydrate chains and their heterogeneity. However, during the last decade the crystal structures of several fungal laccases (Ducros et al., 1998, 2001; Piontek et al., 2002; Bertrand et al., 2002; Hakulinen et al., 2002) and a bacterial laccase (Enguita et al., 2004) have been determined. A revised mechanism for the reduction of dioxygen, based on the X-ray structures of complexes of bacterial laccase, has been proposed recently (Bento et al., 2005).

\section{Materials and methods}

\subsection{Enzyme production and purification}

Cerrena maxima strain 0275 (Mont) Kraisel from the Polyporaceae family producing extracellular laccase was obtained from the Komarov Botanic Institute of the Russian Academy of Sciences (St Petersburg). The fungus was further cultivated at the A. N. Bakh Institute of Biochemistry, RAS. C. maxima was maintained on peptone-glucose medium under conditions of surface and submerged cultivation (Koroleva et al., 2002). At the end of the fermentation, the culture liquids ( $\sim 135-140 \mathrm{ml}$ from one culture flask) were separated by filtration (Whatman filter paper) and cultural filtrates were concentrated to $\sim 25-30 \mathrm{ml}$ by ultrafiltration with a $15 \mathrm{kDa}$ cutoff filter and precipitated with ammonium sulfate at $90 \%$ saturation. Purification was carried out by means of ion-exchange chromatography on DEAE-cellulose, DEAE-Toyopearl 650M (Toyo Soda, Japan) and HPLC [Korolijova (Skorobogat'ko) et al., 1998]. HPLC was performed on a column of Superdex 200 (Pharmacia, Sweden) previously equilibrated with $15 \mathrm{~m} M$ potassium phosphate buffer $\mathrm{pH}$ 6.5. The laccase isoforms were eluted using the same buffer. The main isoform produced was used for further investigations. The homogeneity of the laccase was confirmed by SDS-PAGE electrophoresis (12.6\% acrylamide in $0.2 \mathrm{M}$ Tris-glycine buffer $\mathrm{pH} 8.3$ ) under denaturing conditions (Westermeier, 1993).

\subsection{Assay of the enzymatic activity}

Laccase activity was measured spectrophotometrically with a Hitachi-557 spectrophotometer (Hitachi, Japan) using syringaldazine as a substrate. The reaction mixture contained $3 \mathrm{ml} 0.1 \mathrm{M}$ acetate buffer $\mathrm{pH} 4.5$. The reaction was initiated by the addition of $0.05 \mathrm{ml}$ properly diluted enzyme solution and the increase in absorbance was monitored at $530 \mathrm{~nm}$. One unit of laccase was defined as the amount of enzyme required to cause a change in absorbance of 0.1 unit per minute at $298 \mathrm{~K}$.

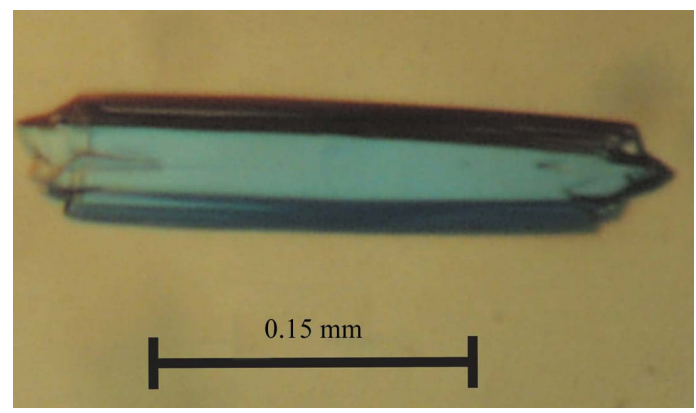

Figure 1

A single crystal of laccase from C. maxima.
Table 1

Crystallographic data-collection and refinement statistics.

Values in parentheses refer to the highest resolution shell (1.949-1.900 $\mathrm{A})$.

\begin{tabular}{|c|c|}
\hline Space group & $P 2_{1} 2_{1} 2_{1}$ (No. 19$)$ \\
\hline Unit-cell parameters $(\AA)$ & $a=52.58, b=77.10, c=130.88$ \\
\hline Monomers per ASU & 1 \\
\hline X-ray source & Consortium beamline X13, DESY, Hamburg \\
\hline Crystal-to-detector distance $(\mathrm{mm})$ & 160 \\
\hline Oscillation range $\left({ }^{\circ}\right)$ & 0.6 \\
\hline Wavelength $(\AA)$ & 0.8068 \\
\hline Resolution $(\AA)$ & $19.28-1.90$ \\
\hline No. of observed reflections & 284698 \\
\hline No. of unique reflections & $41377(2874)$ \\
\hline Redundancy & 6.88 \\
\hline Completeness (\%) & $96.8(90.5)$ \\
\hline Mosaicity $\left({ }^{\circ}\right)$ & 0.172 \\
\hline Average $I / \sigma(I)$ & $14.24(3.91)$ \\
\hline$R_{\text {merge }}(\%)$ & $11.2(31.9)$ \\
\hline$V_{\mathrm{M}}\left(\AA^{3} \mathrm{Da}^{-1}\right)$ & 2.3 \\
\hline Solvent content $(\%)$ & 45.8 \\
\hline Molecular weight $(\mathrm{kDa})$ & 60 \\
\hline$R$ factor $(\%)$ & 18.953 \\
\hline$R_{\text {free }}(\%)$ & 23.835 \\
\hline \multicolumn{2}{|l|}{ R.m.s. deviations } \\
\hline Bond lengths $(\AA)$ & 0.06 \\
\hline Bond angles $\left({ }^{\circ}\right)$ & 1.07 \\
\hline Overall average $B$ factor $\left(\AA^{2}\right)$ & 12.228 \\
\hline \multicolumn{2}{|l|}{ Ramachandran statistics (\%) } \\
\hline Most favoured regions & 86.6 \\
\hline Additionally allowed regions & 12.9 \\
\hline Generously allowed regions & 0.2 \\
\hline Disallowed regions & 0.2 \\
\hline
\end{tabular}

\subsection{Crystallization}

Crystallization of the enzyme was carried out by the hanging-drop vapour-diffusion technique. The crystallizing solution ( $6 \mu$ l volume) contained the protein at a concentration of $8 \mathrm{mg} \mathrm{m}^{-1}$ in $50 \mathrm{mM}$ sodium citrate, $15 \%(w / v)$ PEG 6000, $0.04 M$ Tris-malein-NaOH buffer $\mathrm{pH}$ 5.5. The reservoir solution (volume $0.5 \mathrm{ml}$ ) consisted of $30 \%(w / v)$ PEG 6000, $0.08 M$ Tris-malein-NaOH buffer $\mathrm{pH} 5.5$. Crystals (Fig. 1) were obtained at $298 \mathrm{~K}$ within three weeks.

\subsection{Data collection}

Diffraction data were collected under cryogenic conditions using PEG 400 as a cryoprotectant to $1.9 \AA$ resolution at the Consortium beamline X13 (DESY, Hamburg) with a wavelength of $0.8068 \AA$. All data were processed and merged using the $X D S$ package (Kabsch, 1988). Crystallographic data and data-collection statistics are summarized in Table 1.

\subsection{Structure determination and refinement}

The crystal structure was solved by the molecular-replacement technique using the program MOLREP (Vaguine et al., 1999) from the $C C P 4$ program suite (Collaborative Computational Project, Number 4, 1994). The structure of the laccase from Trametes versicolor (PDB code 1kya; Bertrand et al., 2002) was used as the search model. Only one solution was evident, with an $R$ factor of 0.413 and a correlation coefficient $R_{\text {corr }}$ of 0.642 . The initial steps of refinement were performed using REFMAC (Murshudov et al., 1999). After a few cycles of rigid-body refinement, $R$ and $R_{\text {free }}$ decreased to 0.368 and 0.382 , respectively. Further restrained refinement decreased $R$ and $R_{\text {free }}$ to 0.275 and 0.331 , respectively.

Several cycles of refinement with the $C N S$ program suite (Brünger et al., 1998) were then performed using the Anneal, Minimize, Bgroup and Bindividual options. Stages of CNS refinement were alternated with manual correction of the model and the stereochemical parameters using the program $O$ (Jones et al., 1991) and difference 
electron-density maps with $\left(F_{\mathrm{o}}-F_{\mathrm{c}}\right),\left(2 F_{\mathrm{o}}-F_{\mathrm{c}}\right)$ and $\left(3 F_{\mathrm{o}}-2 F_{\mathrm{c}}\right)$ coefficients. The final stages of model building involved the adjustment of the $\mathrm{Cu}$-ion occupancies, the identification of three carbohydrate chains $\mathrm{N}$-linked to surface asparagine residues, the treatment of disordered side chains and a full analysis of the solvent structure. The structure of the $C$. maxima laccase was refined to an $R$ factor and $R_{\text {free }}$ of 18.953 and $23.835 \%$ (Table 1 ), respectively, applying all data to $1.9 \AA$, and was finally validated using the program PROCHECK (Laskowski et al., 1993).

\section{Results and discussion}

The electron-density maps are of good quality and have allowed tracing of the polypeptide chain throughout the molecule (Fig. 2). In the initial stages of refinement, four copper sites were revealed in the $\left(F_{\mathrm{o}}-F_{\mathrm{c}}\right)$ electron-density maps. These provided further confirmation of the correct solution of the structure, since the $\mathrm{Cu}$ atoms were not included in the starting coordinates. The occupancies of the $\mathrm{Cu}$ ions in C. maxima laccase were refined with the program SHELX97 (Sheldrick \& Schneider, 1997). Some depletion of the type 1 and type 2 copper ions was observed: the occupancies of $\mathrm{Cu} 1, \mathrm{Cu} 2, \mathrm{Cu} 3$ and $\mathrm{Cu} 4$ were $0.8,1.0,1.0$ and 0.83 , respectively. It was possible to unambiguously identify 65 side chains of the unknown sequence of the C. maxima laccase using $\left(F_{\mathrm{o}}-F_{\mathrm{c}}\right)$ difference maps at $1.9 \AA$ resolution.

The overall molecular structure of the C. maxima laccase (Fig. 2) shows a high homology with other laccase structures reported previously (Lindley, 2001). The enzyme is a monomer consisting of three cupredoxin-like domains (Fig. 2): I (residues 1-131), II (residues 132-309) and III (residues 310-499). Domain I comprises 11 $\beta$-strands and one helix. The second domain comprises $11 \beta$-strands and the third domain contains six $\beta$-strands and three helixes. The long $\alpha$-helix at the C-terminus of the laccase is stabilized by a disulfide bridge between Cys 85 and Cys488 (2.05 $\AA$ ). A second disulfide bridge, Cys117-Cys205 (2.02 ̊), links domains I and II. Both the $\mathrm{N}$ - and $\mathrm{C}$-terminal amino acids are hydrogen bonded to the main part of the protein and are well defined in the electron density.

The mononuclear copper site is located in domain III, close to the potential substrate-binding cavity. In a similar manner to other multi-

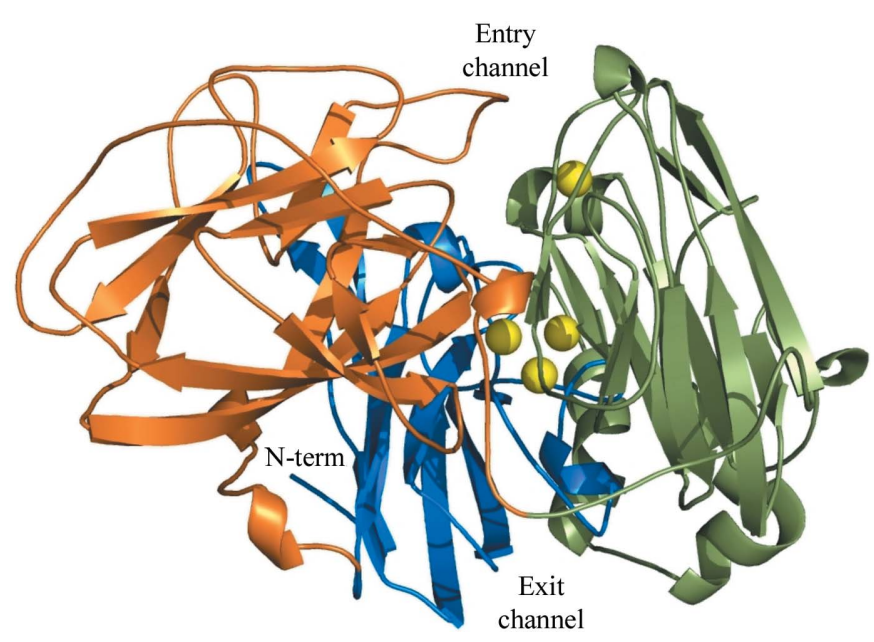

Figure 2

The overall structure of the laccase from C. maxima at $1.9 \AA$ A resolution showing the three domains (coloured blue, orange and green for domains I, II and III, respectively) and the position of the copper centres (yellow spheres). This figure was prepared using the ViewerLite program. copper oxidases, the cation has planar trigonal coordination via cysteine residue Cys453 and the two histidines His395 and His458. Phe463 and Ile455 lie on either side of the plane, with closest distances of 3.66 and $3.55 \AA$, respectively. Ile 455 is near to the putative substrate cavity. Other fungal laccases have aliphatic residues in this axial position. In the C. cinereus laccase (Ducros et al., 2001), the axial position is occupied by Leu 462 at a distance of $3.51 \AA$ from the copper ion. In the T. versicolor laccase (Piontek et al., 2002), there is a phenylalanine in this position at a distance of $3.6 \AA$. This configuration differs from that found for ascorbate oxidase (Messerchmidt et al., 1992), the cotA laccase from Bacillus subtilis (Enguita et al., 2003) and CueO from Escherichia coli (Roberts et al., 2002), where a methionine $S$ atom is in an axial position at a distance of about $3.0 \AA$ from the copper ion.

The trinuclear copper cluster is localized between domains I and III and is bound to the protein by eight histidines, four each from domains I and III; access to the ions is provided by two solvent channels. Regions of high electron density were also identified at the periphery of the molecule in the vicinity of Asn54, Asn217 and Asn436 and have been interpreted as N-linked glycosylation sites. Two of the glycans of the C. maxima laccase structure form a covalently bonded framework, which appears to strengthen the crystal packing and obviously supports the growth of well ordered crystals suitable for X-ray analysis. Further studies are currently under way to investigate the precise conditions under which these covalent bonds between glycan chains are formed for the C. maxima laccase.

This project was supported by BMBF (Bundesministerium für Forschung und Wissenschaft, under contract RUS/214). We would like to thank the Komarov Botanic Institute of the Russian Academy of Sciences (St Petersburg) for generously donating the C. maxima fungus strain.

\section{References}

Adman, E. T. (1991). Curr. Opin. Struct. Biol. 1, 895-904.

Bento, I., Martins, L. O., Lopes, G. G., Carrondo, M. A. \& Lindley, P. F. (2005). Dalton Trans., pp. 3507-3513.

Bertrand, T., Jolivalt, C., Briozzo, P., Caminade, E., Joly, N., Madzak, C. \& Mougin, C. (2002). Biochemistry, 41, 7325-7333.

Brünger, A. T., Adams, P. D., Clore, G. M., DeLano, W. L., Gros, P., GrosseKunstleve, R. W., Jiang, J.-S., Kuszewski, J., Nilges, M., Pannu, N. S., Read, R. J., Rice, L. M., Simonson, T. \& Warren, G. L. (1998). Acta Cryst. D54, 905-921.

Collaborative Computational Project, Number 4 (1994). Acta Cryst. D50, 760-763.

Ducros, V., Brzozowski, A. M., Wilson, K. S., Brown, S. H., Ostergaard, P., Schneider, P., Yaver, D. S., Pedersen, A. H. \& Davies, G. J. (1998). Nature Struct. Biol. 5, 310-316.

Ducros, V., Brzozowski, A. M., Wilson, K. S., Ostergaard, P., Schneider, A., Svendson, A. \& Davies, G. J. (2001). Acta Cryst. D57, 333-336.

Enguita, F. J., Marcal, D., Martins, L. O., Grenha, R., Henriques, A. O., Lindley, P. F. \& Carrondo, M. A. (2004). J. Biol. Chem. 279, 23472-23476.

Enguita, F. J., Martins, L. O., Henriques, A. O. \& Carrondo, M. A. (2003). J. Biol. Chem. 278, 19416-19425.

Hakulinen, N., Kiiskinen, L. L., Kruus, K., Saloheimo, M., Paananen, A., Koivula, A. \& Rouvinen, J. (2002). Nature Struct. Biol. 9, 601-605.

Jones, T. A., Zou, J.-Y., Cowan, S. W. \& Kjeldgaard, M. (1991). Acta Cryst. A47, 110-119.

Kabsch, W. (1988). J. Appl. Cryst. 21, 916-924.

Koroleva, O. V., Gavrilova, V. P., Stepanova, E. V., Lebedeva, V. I., Sverdlova, N. I., Landesman, E. O., Yavmetdinov, I. M. \& Yaropolov, A. (2002). Enzyme Microb. Technol. 30, 573-580.

Korolijova (Skorobogat'ko), O. V., Stepanova, E. V., Gavrilova, V. P., Morozova, O. V., Lubimova, N. V., Dzchafarova, A. N., Jaropolov, A. I. \& Makower, A. (1998). Biotechnol. Appl. Biochem. 28, 47-54.

Laskowski, R. A., MacArthur, M. W., Moss, D. S. \& Thornton, J. M. (1993). J. Appl. Cryst. A47, 110-119. 


\section{protein structure communications}

Lindley, P. F. (2001). Multi-Copper Oxidases, edited by I. Bertini, A. Sigel \& H. Sigel, pp. 763-911. New York: Marcel Dekker.

Malmstrom, A. G. (1982). Annu. Rev. Biochem. 51, 21-59.

Mayer, A. M. \& Staples, R. C. (2002). Phytochemistry, 60, 551-565.

Messerschmidt, A., Ladenstein, R., Huber, R., Bolognesi, M., Avigliano, L., Petruzzelli, R., Rossi, A. \& Finazzi-Agro, A. (1992). J. Mol. Biol. 224, 179-205.

Murshudov, G. N., Vagin, A. A., Lebedev, A., Wilson, K. S. \& Dodson, E. J. (1999). Acta Cryst. D55, 247-255.

Piontek, K., Antorini, M. \& Choinowski, T. (2002). J. Biol. Chem. 277, $37663-$ 37669.

Reinhammar, B. (1984). Copper Proteins and Copper Enzymes, edited by R. Lontie, pp. 1-36. Boca Raton, FL, USA: CRC Press.
Reinhammar, B. (1997). Multi-Copper Oxidases, edited by A. Messerschmidt, pp. 168-200. Singapore: World Scientific.

Roberts, S. A., Weichsel, A., Grass, G., Thakali, K., Hazzard, J. T., Tollin, G., Rensing, C. \& Montfort, W. R. (2002). Proc. Natl Acad. Sci. USA, 99, 27662771.

Sakurai, T. (1992). Biochem. J. 284, 681-685.

Sheldrick, G. M. \& Schneider, T. R. (1997). Methods Enzymol. 227, 319-343.

Thurston, C. F. (1994). Microbiology, 140, 19-26.

Vaguine, A. A., Richelle, J. \& Wodak, S. J. (1999). Acta Cryst. D55, 191205.

Westermeier, R. (1993). Electrophoresis in Practice. Weinheim: VCH.

Xu, F., Shin, W., Brown, S. H., Wahleithner, J. A., Sundaram, U. M. \& Solomon, E. I. (1996). Biochim. Biophys. Acta, 1292, 303-311. 